\title{
Modeling Economic Growth Fuelled by Science and Technology
}

\author{
- Leonardo Costa Ribeiro *

 \\ - Ricardo Machado Ruiz** \\ - Eduardo da Motta e Albuquerque ${ }^{\star \star \star \star \star}$
}

\begin{abstract}
Resumo
Este artigo propõe um modelo de simulação para investigar a contribuição da ciência e da tecnologia para o crescimento econômico. O ponto de partida são os sistemas nacionais de inovação, um conceito que sintetiza a capacitação tecnológica das nações. Desta forma, o modelo pode preservar simplicidade e parcimônia. Os dados coletados (patentes, artigos e PIB e população, para 183 países) indicam uma forte correlação entre ciência, tecnologia e renda. Três exercícios com simulações são realizados para diversos momentos do tempo, mostrando a progressiva aderência do modelo a essas variáveis tecnológicas.
\end{abstract}

\section{Palavras-Chave}

sistemas nacionais de inovação, patente, ciência, competitividade, crescimento econômico

\begin{abstract}
This paper suggests a simulation model to investigate how science and technology fuel economic growth. This model is built upon a synthesis of technological capabilities represented by national innovation systems. This paper gathers data of papers and patents for 183 countries between 1999 and 2003, as well as GDP and population for 2003. These data show a strong correlation between science, technology and income. Three simulation exercises are performed. Feeding our algorithm with data for population, patents and scientific papers, we obtain the world income distribution. These results support our conjecture on the role of science and technology as sources of the wealth of nations.
\end{abstract}

\section{Keywords}

national system of innovation, patent, science, competitiveness, economic growth

\section{JEL Classification}

$\mathrm{O}, \mathrm{O} 3$

+ The Brazilian agencies CNPq and Fapemig partially supported this work. We thank Thais Henriques, Leandro Silva, Ana Luíza Araújo, Marcela de Castro, Felipe da Mata e Luíza M. Franco for research assistance, and two anonymous referees of this journal for their criticisms and suggestions. Any remaining errors are ours.

* Department of Economics, Universidade Federal de Minas Gerais (UFMG). E-mail: Icr@cedeplar.ufmg.br.

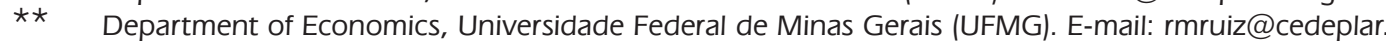
ufmg.br.

$\star \star \star \quad$ Department of Physics, Universidade Federal de Ouro Preto (UFOP). E-mail: atb@iceb.ufop.br.

$\star \star \star \star$ Department of Economics, Universidade Federal de Minas Gerais (UFMG). E-mail: albuquer@cedeplar. ufmg.br.

Contact address: Departamento de Economia - FACE - Universidade Federal de Minas Gerais (UFMG) - Belo Horizonte - MG - Brazil. CEP: 30161-970.

(Recebido em outubro de 2008. Aceito para publicação em agosto de 2009). 


\section{Science and Technology Fuelling Economic Growth}

This paper presents a simulation model to investigate how science and technology fuel economic growth. This model is built upon two different lines of investigation related to the evolutionary approach: first, national systems of innovation (NSIs) (FREEMAN, 1988; NELSON, 1993); second, the evolutionary modeling strategy based on simulation models (NELSON; WINTER, 1982; DOSI, 2000). Since the concept of NSI is a synthesis of technological capabilities acquired by countries, the use of this concept allows our simulation model to be parsimonious. What are the theoretical foundations that underline the concept of national innovation systems? National innovation system (NSI) is a concept that shows how a complex interplay of different actors (firms, universities, public labs, governments, financial institutions etc) pushes the technological development of nations. NSI puts the engine of technological progress at the centre of the process of economic development.

Innovation system is a concept developed by Freeman (1988), Nelson (1988) and Lundvall (1988) in a book that is the first organized presentation of the evolutionist approach as a whole (DOSI et al., 1988). The first round of this elaboration, at large, took place during the 1970s, with the publication of three pioneering works: Freeman (1974); Rosenberg (1976) and Nelson and Winter (1977). These works involved a lot of theoretical synthesis and dialogue with previous elaboration. ${ }^{1}$ The result of this first round of theoretical elaboration is the ground work for an explosion of empirical, theoretical and comparative studies using the evolutionary elaboration as reference. Freeman (1994) and Dosi (1997) describe the rich array of subjects worked out by evolutionists after this first round. A second round of theoretical elaboration takes place during the 1980s and the 1990s: the concept of NSI is presented (FREEMAN, 1988; NELSON, 1988; LUNDVALL, 1988).

Three contributions are specially important and representative: Nelson (1993), Lundvall (1992) and Edquist (1997). The NSI as a synthesis of previous elaboration opened new room for further advances in the evolutionary approach and to broaden the concept of innovation systems. The third round of evolutionary elaboration on NSIs emphasizes new subjects in the research agenda: the connections between NSIs, economic growth and development, convergence and divergence in a global arena. Freeman (1995) is representative of this new round. Dosi, Freeman and Fabiani (1994), Fagerberg (1994), and Nelson (1998) are representatives of evolutionists' interventions in the debate regarding economic growth. Dosi, Freeman and Fabiani (1994, p. 14-15) put forward how has the correlation between technology and wealth evolved throughout the 20th century. This point is easily integrated

1 See Nelson and Winter (1982, p. 33-45) for a summary of "allies and antecedents of evolutionary theory". 
with other works, as Narin et al. (1997) that show the increasing role of science and technology as sources of economic development. ${ }^{2}$ Our paper may be seen as part of a fourth round of this evolutionary elaboration, initiated by Lundvall's Globelics network in 2003 (www.globelics.org) and by Nelson's Catch Up Project (2005). These initiatives are attempts to include less-developed countries as important subjects of the evolutionary agenda. Since our data, model and simulations include all countries of the World, our paper contributes to this last round of evolutionary elaboration.

Why should we use simulation techniques for our modeling? The evolutionary economists, in a tradition pioneered by Nelson and Winter (1982), have used simulation techniques to investigate economic change. Nelson and Winter explain why the use of simulation techniques is adequate for evolutionary theorists. The main reasons to opt for simulation techniques are: theoretical concerns ("some strong qualitative beliefs about a number of components of the model" without being "rigid about the precise form they should take", p. 207), tractability, possibility of manipulation of certain variables of the model, and the possibility of "generating macro aggregates ... through the route of building them up from microeconomic data" (p. 207-209). They warn against "the most serious problem with many simulation models": lack of transparency (p. 208). Nevertheless they conclude that it is possible to "aim for and achieve a considerable amount of transparency in a simulation model by keeping it relatively simple and clean" (p. 208).

Simulation models have been widely used as tools for investigation of firm competition, path-dependence, market structure, technological change at firm and industry levels etc. These are lines of inquiry introduced by Nelson and Winter (1982, specially Part III: Schumpeterian competition). Nelson (1995) and Dosi (2000) are good surveys of this literature. Silverberg and Verspagen (2005) present an updated version of this line of inquiry.However, our line of investigation goes into another direction: models of multi-country growth. Nelson and Winter also pioneered this line, with their "evolutionary model of economic growth" (1982, chapter 9). To simulate the United States economy between 1909 and 1949, Nelson and Winter's model involves: (a) 35 firms, producing the same homogeneous product (GNP), using labor and capital; (b) firms with a certain productive technique and a stock of capital; (c) a simple decision rule; (d) a wage rate; (e) gross returns to capital and (f) transition rules (resulting from search procedures and investment rules (p. 209-217). The model generates "aggregate time series with characteristics corresponding to those of economic growth in the United States" (p. 226). Since 1982 there is a stead growth of the literature using evolutionary models and simulation techniques. However, models concerning growth of nations are relatively scarce; an

2 See references on this subject in Bernardes and Albuquerque (2003). 
important exception is the work of Aversi et al. (2000). Built upon stylized facts summarized by Dosi et al. (1994), the model presents a multi-country model that "tries to move some steps in this direction by microfounding country dynamics on some stylized company specific processes of innovation and imitation" (p. 535). It simulates one world economy with L countries, each country with M sectors and $n$ firms. The model is very detailed in its specifications, defining the procedures for search and imitation, the behavior rules ("totally routinized": R\&D investments, prices, firms competitiveness and firms growth), market dynamics, aggregate dynamics and national accounts and the general properties of the model (endogenous technological shocks, shocks propagation, sources of persistence and non-linear processes of interactions among firms and characteristics of new firms). Their model has 23 equations.

Our model differs from the Aversi et al. (2000) in two simple ways. First, while they try to add microfoundations to the model, our model is built upon the synthesis of technological capabilities represented by the concept of NSI. Second, in their model the main agents are firms, while in our model the agents are countries, thus the interaction among countries is mainly guided by the NSI and other country variables, such as population and a general price index level. Our line of inquiry led us to search for parsimonious models, which mean few equations, variables synthetic enough to describe key features of modern economic development. Therefore the use of NSI and its two dimensions (science and technology) to summarize these relationships. ${ }^{3}$

NSI is a complex institutional arrangement, product of long historical development that involves diverse actors such as firms, universities and public research institutes, governments, legal systems, articulation with financial systems (public and private). These actors interact among themselves, generating self-enforcing dynamics and mutual feedback between them. This paper focuses on two dimensions of this broader institutional arrangement: 1) the scientific dimension - universities and public research institutes are the key components here; 2) the technological dimension - firms are the key components. These two dimensions with their key components are part of NSIs and are embedded in their institutional formation. There is a simplification in our decision to use these two dimensions in our modeling exercise to summarize a NSI. However, these two dimensions are very representative of a NSI. On the one hand, because the existence and the strength of firms depend upon broad factors as financial conditions, educational and skills, and macroeconomic environment. On the other, because the size, quality and diversity of universities and

3 In a presentation of one preliminary version of this model in a Conference of Physics (RUIZ et al., 2005), some participants presented tough criticisms against the model because it had too many variables (four variables or country dimensions: GDP, population, scientific capability, and technological capability). 
PRIs depend upon other factors as the level of nation building, the state of public finance, and income distribution. Therefore, the size, variety and quality of both the technological and scientific dimensions may be a good summary of the overall conditions of a NSI. In a previous paper (BERNARDES; ALBUQUERQUE, 2003) we have suggested a highly simplified model with three different regimes of interaction. In this simplified model, the interactions between these two dimensions are crucial for economic growth, since firms implement innovations and are the creators of jobs, income, and wealth, and they need to use the scientific institutions to feed their innovative activities. In that simplified model, the causality runs both ways, since on the one hand science and technology fuel economic growth, but on the other hand, economic growth feeds science and technology (with more resources to finance science and engineering fields, public and private investments for firms' creation, conditions to finance private $R \& D$ etc).

What are the quantitative indicators that may capture the scientific dimension and the technological dimension? Patent statistics are used as a proxy of technological capabilities and publication statistics are a proxy of scientific capabilities. Therefore they together may summarize the main features of national innovation systems. Of course, papers are not a perfect measure of scientific production, and patents are not a perfect measure of technological innovation. The literature has used these data and recognized their problems and shortcomings (see MÖED; GLÄNZEL; SCHMOCH, 2004). Scientific papers, the data collected by the ISI, have various shortcomings, from language bias to the quality of research performed. Besides, there could be important research effort for local needs that do not translate in international papers, but only in national publications not captured by the ISI database. Patents, the USPTO data, also have important shortcomings, from commercial linkages with the US to the quality of the patent. Again, local innovation necessarily is limited to imitation in the initial phases of development, and imitation or minor adaptations do not qualify for a patent in the USPTO.

Despite these problems, these two datasets appear to provide useful information for research. This paper gathers data of papers and patents for 183 countries between 1999 and 2003. The option for collecting a broad sample of countries is justified by the inclusion of countries from different stages of development, which allows a comparison between developed and less-developed countries (including the transitional position of catching up countries). This data set uses the average for the period 1999-2003, in order to include more countries, mainly those less developed, with very low scientific and/or technological production.

Figure 1 organizes the data in a three-dimensional plot, where the $\log 10$ of the GDP per capita (US\$, PPP, according to the World Bank, for 2003) is plotted against 
the $\log 10$ of the number of articles per million of inhabitants $\left(\mathrm{A}^{*}\right)$ and the $\log 10$ of the number of patents per million of inhabitants $\left(\mathrm{P}^{*}\right)$. The data are an average for the years 1999-2003. Only countries with data available and scores different from zero are represented.

Figure 1 shows a strong correlation between science, technology and wealth of nations. Table 1 shows a Correlation Matrix between GNP, patents, articles, and population. There are strong relationships among these variables, which indicate that there is some system that connects them. Figure 2 shows the projection of these data on the articles-patents plane. Ribeiro et al. (2006b) apply a superparamagnetic clustering technique and find three groups of countries. Hence, they suggest there are three "regimes" that summarizes different levels of development and different types of NSI.



Plot of $\log 10 \mathrm{GDP}$ per capita (2003) versus $\log 10 \mathrm{~A}^{8}$ (articles per million of inhabitants) versus $\log 10 \mathrm{P*}$ (patents per million of inhabitants). The data for aticles and patents represent an average for the years 1999-2003.

Figure 1 - GDP Per Capita vs. Articles vs. Patents (1999-2003) 
Table 1 - Correlation Matrix

\begin{tabular}{lccccccc}
\hline & GDP & GDPpc & POP & PATpc & ARTpc & PAT & ART \\
\hline GNP & 1.0000 & & & & & & \\
GNPpc & 0.3606 & 1.0000 & & & & & \\
POP & 0.2689 & -0.0786 & 1.0000 & & & & \\
PATpc & 0.6578 & 0.6752 & 0.0385 & 1.0000 & & & \\
ARTpc & 0.2631 & 0.8053 & -0.0726 & 0.7084 & 1.0000 & & \\
PAT & 0.9691 & 0.3015 & 0.1550 & 0.6577 & 0.2037 & 1.0000 & \\
ART & 0.9869 & 0.3950 & 0.2804 & 0.6743 & 0.3335 & 0.9380 & 1.0000 \\
\hline
\end{tabular}

Data Source: ISI, USPTO and World Bank, authors' elaboration.

These "regimes" suggest that there are different mechanisms inside NSI. The interactions between science and technology seem to be operating more fully in the countries of the most developed regime (regime 3, represented by circles in Figure 2). Conversely, countries in clusters represented by triangles (regime 2) and by squares (regime 1) lack critical mass in the scientific infrastructure that weakens (or even blocks) the feedbacks between science and technology that pushes economic growth.

Ribeiro et al. (2006b) suggest that as the "regimes" change, the number and the channels of interactions between scientific infrastructure, technological production and economic growth also change. As the country evolves, more connections are turned on and more interactions operate. This process is non-linear and subject to structural changes. The highest regime is the case where all connections and interactions are working. As long as the development takes place, the role of other aspects, e.g. natural resources, decreases in the causation of economic growth. As a country upgrades its economic position, its economic growth is increasingly caused by its scientific and technological resources. The feedbacks between them contribute to explain why the modern economic growth is fuelled by strong scientific and technological capabilities.

This paper's model is a result of previous work. Bernardes and Albuquerque (2003) present a discussion concerning science and technology in less-developed countries, while Ruiz et al. (2005) initiates our modeling elaboration. Ribeiro et al. (2006a) concludes this elaboration and suggests a first model and Ribeiro et al. (2006b) cluster countries in three different "regimes", representing different stages of NSI formation. 


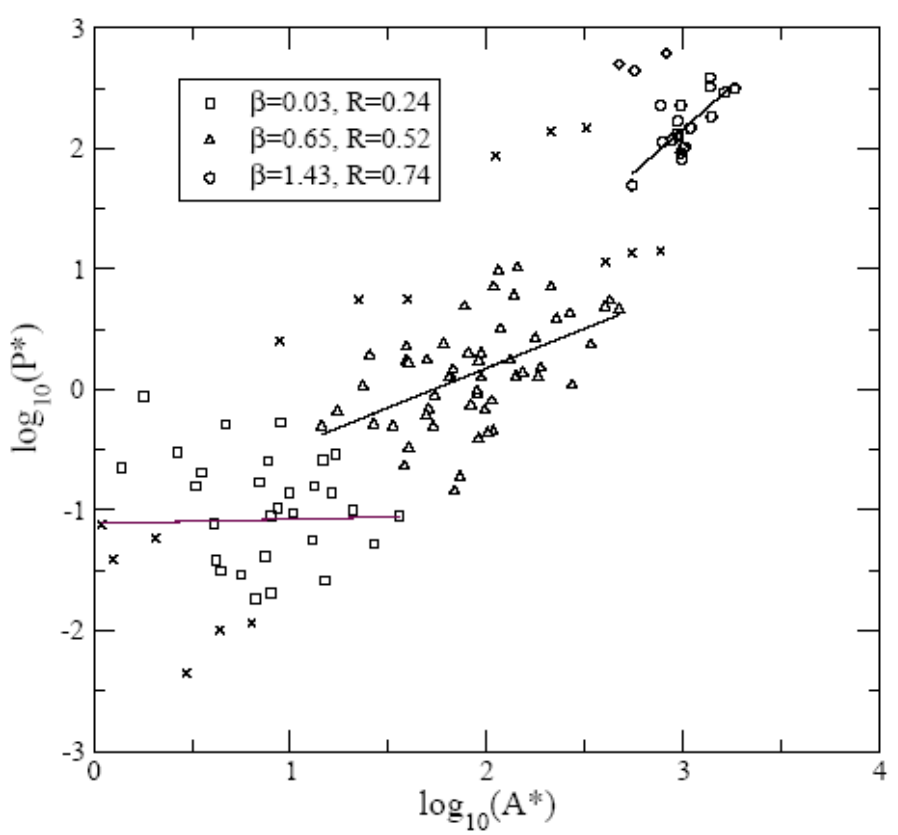

Note: Clusters obtained in applying the super-paramagnetic clustering technique. Three main groups are clearly distinguished in this figure. The circles represent countries in regime III, triangles stand for those in regime II, and squares represent countries in regime I. Note that a small group of three countries split at the top of the figure. They are Taiwan, Japan, and the United States. For details, see Ribeiro et al. (2006b).

Source: Ribeiro et al. (2006b).

Figure 2 - Three Regimes (1999-2003)

This paper is organized in four sections, including this introduction (Section 1). Section 2 presents our model. Section 3 performs the simulations. Section 4 concludes the paper.

\section{Innovation and Imitation in a Multi-Country Model}

This section presents a new model, based on our previous work. Ruiz et al. (2005) is the first draft and Ribeiro et al. (2006a) present our first developed model. The insights and discussions provided by these previous papers contributed for an improvement: a country may innovate even if it has not had income reductions. In the former model, a country only would try to improve its technological position if its income were reduced. This reasoning is in line with Nelson and Winter 1982 model, where "only those firms that make a gross return on their capital less than the target level of 16 percent engage in search" (p. 211). This seems not to be the case, as 
theory and evidence show that leading countries innovate in a very systematic way. Thus, in this version of the model, a country may improve its technology without suffering income losses. In our model, the world economy is designed as a network of agents (countries), and the interactions among these countries are represented by functions that connect their prices, demands, technologies, and incomes. Starting from random values for the country technology, the artificial world economy selforganizes itself and creates hierarchies of countries that are closer to the real world (as identified by our empirical findings). In the beginning of the simulation, there is an unbalanced network, each point (a country) in the configuration space with its own set of features. However, interactions are necessary (within countries and between them) to produce a specific hierarchy. This hierarchy may correspond (or not) to the world captured by data (GDP per capita).

The basic variables for each country are (a) $L i$, its population or labor force; (b) its income or gross domestic product $Y i$ (the wage or per capita income being $\mathrm{Wi}=\mathrm{Yi}$ / $\mathrm{Li}$ ); (c) patents and (d) scientific papers. The country economic structure is given by four equations, described as follows:

\subsection{Price and Production}

The equations that define the level of production and price are:

$$
\begin{aligned}
& Q_{i t}=\left(T_{i t}, L_{i t}\right)+V_{i t-1} \\
& P_{i t}=\left(Y_{i t} / Q_{i t}\right) \\
& P_{i t}=\text { Yit } /\left[\left(T_{i t}, L_{i t}\right)+V_{i t-1}\right]
\end{aligned}
$$

Where, $Q_{i}$ is the amount of goods produced by country $i, T_{i}$ represents country technology, $L_{i}$ stands for population or labor force, and $V_{i}$ is the unsold good of preious period. The country income (US\$ GDP) is $Y_{i}$ and $P_{i}$ is the price of one unit of good $Q_{i}$. Population (or labor force) is constant, thus $Q_{i}$ depends mostly on $T_{i}$, which is an output of the NSI. The price level is set by an adaptive rule: everything else constant, unsold stocks and decreasing national income reduce prices and increase competitiveness, and falling inventory and raising income do the opposite. ${ }^{4}$

4 Possas et al. (2001) set firm price as a function of desired price and average price weighted by a degree of monopoly. Such price rule is a version of the so-called "full cost principle" in oligopolist conditions. This modeling is an adequate representation when the agents are firms. However, in our model the agent are countries, which require another modeling approach. This approach is necessary because there are no strategic interactions among countries, as in oligopolistic industries. 


\subsection{Competitiveness, Market Share and Demand}

The country competitiveness $C i$ has an inverse relation with its price:

$$
\mathrm{C}_{\mathrm{it}}=\left(1 / P_{i t}\right)
$$

The global competitiveness $C g$ is the country competitiveness $C_{i}$ weighted its market share $M_{i}$ (the participation of the country in the world economy measured by its income):

$$
M_{i t}=Y_{i t} / \sum Y_{i t} \quad C g_{t}=\sum\left(M_{i t} . C_{i t}\right)
$$

A replicator dynamics equation models the changes of country market share (equation 5 and 6). The replicator dynamics is routinely used in evolutionary game theory, versions of cobweb models and other dynamic sets. It is used to represent sluggish changes in behaviors; in this case the $\sigma$ is the speed of the market share changes to asymmetries in the country and the global competitiveness.

$$
M_{i t}=M_{i t-1} \cdot\left[1+\sigma \cdot\left\{\left(C_{i t} / C_{g t}\right)-1\right\}\right], \text { where } 0<\sigma<1 \text {, and } \sum M_{i t}=1
$$

Thus, the country demand $D i$ (unit of goods) is given by:

$$
Y_{g t}=\sum Y_{i t} D_{i t}=\left(M_{i t} . Y_{g t}\right) / P_{i t}
$$

The model has an important assumption: it has an implicit fix exchange rate regime. Thus, the aggregate income adjusts following the relative country competitiveness, which means that the nominal and per capital income increase or decrease to meet the income level given by $M_{i t} . Y_{g t}$. There is no trade and exchange rate policy that could minimize or maximizes the trade level. ${ }^{5}$

\subsection{Income and Inventory}

There are recurrent disequilibria on the amount of goods demanded and supplied. Thus, three simple rules were created:

When $D_{i t}=Q_{i t}$, then: $Y_{i t}=P_{i t} \cdot Q_{i t}=P_{i t} . D_{i t}, V_{i t}=0$

5 To add trade and exchange rate policy as strategic behaviors of countries it would require setting a reaction function driven by changes in real income, employment level when wages are constant, or export and import trade levels. That could be a next step in this model: the inclusion of economic police regimes. 


$$
\begin{aligned}
& \text { When } D_{i t}>\mathrm{Q}_{\mathrm{it}} \text {, then: } Y_{i t}=P_{i t} \cdot Q_{i t}, V_{i t}=0 \\
& \text { When } D_{i t}<\mathrm{Q}_{\mathrm{it}} \text {, then: } Y_{i t}=P_{i t} . D_{i t}, V_{i t}=\left(Q_{i t}-D_{i t}\right) \\
& \mathrm{Vg}_{\mathrm{t}}=\Sigma V_{i t}=\Sigma\left(Q_{i t}-D_{i t}\right) \\
& \operatorname{Rg}_{t}=\Sigma R_{i t}=\Sigma\left[P_{i t} .\left(D_{i t}-Q_{i t}\right)\right]
\end{aligned}
$$

Where $Y i$ is the income that result from the local and international trade, $R_{i t}$ and $R g_{t}$ are the country and global residual income (income not spent), and $V_{i t}$ and $V g_{t}$ are the country and global stock of unsold goods. The country residual income is proportional to its market share $M i$ :

$$
R_{i t}=R g_{t} . M_{i t}
$$

In the first case above (equations 7$)$, all goods are sold $\left(V_{i t}=0\right)$ and there are no residual income $\left(R_{i}=0\right)$, which means the system is in equilibrium (thus $R g=0$ and $V g=$ $0)$. In the second case (equation 8$)$, there is an excess of demand $\left(R g_{t}>0\right)$, there is no inventory $\left(V g_{t}=0\right)$ and consumers do not spend all their incomes, which means residual income $R_{i t}$ return to countries (equation 9 ). In the third case (equation 10 ) there is an excess of supply $\left(V_{i t}>0\right)$ and all income is spent $(\operatorname{Rg}=0)$. At the equilibrium there would be no inventory $(V g=0)$ and no residual income $(R g=0)$. However, as one can check, the equations 16 to 18 keep the system out of the equilibrium.

Therefore, the current country income $Y_{i t}$ is the income from trade $Y_{i t-1}$ plus the income not spent in the previous period $R_{i t-1}$ (residual income). The wage (or per capita income) is the country income distributed among its laborers (population).

$$
\begin{aligned}
& Y_{i t}=Y_{i t-1}+R_{i t-1} \\
& W_{i t}=Y_{i t} / L_{i t}
\end{aligned}
$$

The global income is the sum of all country incomes:

$$
Y g_{t}=\sum Y_{i t}
$$

\subsection{Technological Change}

Countries change their technology in order to increases its competitiveness and wealth. Technology depends on the previous level of its own knowledge $\left(T_{i t-1}\right)$ and 
on the technological information grabbed from international sources $\left(\operatorname{Tg}_{t-1}\right)$. Country capabilities to create new technologies are represented by patents and articles per capita $\left(P T_{i}\right.$ and $\left.A T_{i}\right)$, which are proxies for country's technological and scientific capabilities:

$$
\begin{aligned}
& T_{i t}=T_{i t-1}+N_{i t} \\
& N_{i t}=\left(T g_{t} . P T_{i} \cdot A T_{i}\right)^{1 / 3}, \text { where } 0<N_{i} \\
& T g_{t}=\sum\left(M_{i t} . T_{i t-1}\right)
\end{aligned}
$$

The coefficient $N_{i}$ is a proxy to the NSI, which corresponds to the countries' innovation capabilities $\left(A T_{i}\right.$ and $\left.P T_{i}\right)$ plus the spillovers of technologies of the global economy $\left(\mathrm{Tg}_{t}\right)$. Therefore, the national system of innovation $N_{i}$ summarizes the country capabilities to imitate and innovate.

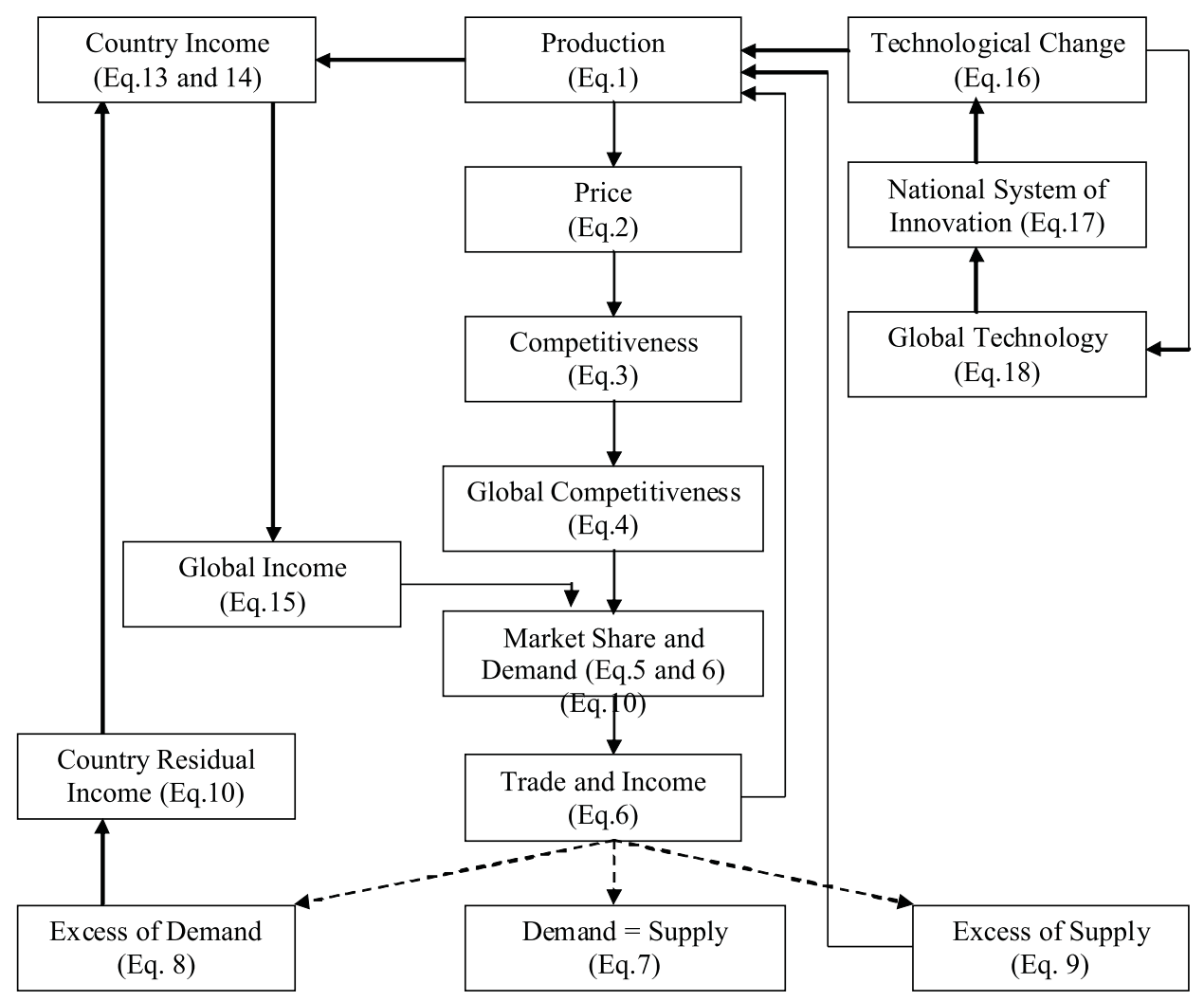

Draw 1 - Model Structure 


\section{Simulations and Results}

We chose the initial values of our simulations (initial countries' incomes, $Y_{t}{ }^{0}$ ). The system evolves accordingly the algorithm described in Section 4. Then we monitor the evolution of income $(Y)$ and of residual income $(R)$ until the system reaches a stationary state. Typically (as in RIBEIRO et al., 2006a), we use three alternative initial conditions for the wealth of nations:

(a) all countries start with their real GDPs;

(b) all countries have the same GDP - each country receives $\sum_{i=1}^{N_{c}} Y_{i} / N_{c}$, where $N c$ is the number of countries (183); and

(c) we give random values to $Y_{0}$.

In all simulations the initial level of technological development $\left(T_{0}\right)$ is ran domly selected between $(0,1]$.

\subsection{First Simulation: Initial Random GDPs}

In a first simulation exercise, we present the case of initial random values of $Y_{0}$ (option number 3, above). Figure 3a shows the evolution (1,000 simulation steps) of global residual income $\mathrm{Rg}$ for this case. In the beginning (the first 70 simulation steps) there are huge differences between supply and demand. This mismatch is represented by the high values of global residual income $(R g)$. As the simulation goes on, the global residual income decrease significantly and the system evolves to a stationary state (near 400 simulation steps). Figure 3b shows a similar pattern for unsold goods.


Figure 3 - Residual Income (3a) and Unsold Goods (3b) (1,000 Simulation Steps, Logaritmic Scale) 
As the system reaches a stationary state (according to Figures 3a and 3b), we compare the real and the simulated values. Figure 4 presents this comparison $\left(Y_{\text {real }}\right.$ versus $\left.Y_{\text {simulated }}\right)$, after 1,000 simulation steps. There is a correlation between the real and simulated values $\left(\beta=1.10\right.$ and $\left.R^{2}=0.98\right)$. This correlation suggests that the assumptions regarding the guiding force of technological capability $(T)$ to organize the simulated world replicate well the real world, however, the slope $\beta$ of the regression deserves some commentaries. Regarding the correlation between simulated and real values, Figure 4 shows that for higher $Y$ there is a smaller dispersion of points (countries) vis-à-vis the linear regression. This suggests that for richer countries the role of science and technology as source of their wealth is stronger than for poorer countries. Inversely, for lower $Y$ there is a greater dispersion of points (countries) vis-à-vis the regression line. This greater dispersion may indicate that for these poorer countries "other" factors beyond science and technology (natural resources endowments, geopolitical conditions, etc) have stronger role as source of their wealth. These findings seem to be in line with a simple model presented in a previous paper (see BERNARDES; ALBUQUERQUE, 2003).

Regarding the slope of the regression line $(\beta=1.10)$, Figure 4 shows both overestimation and underestimation of wealth. The wealth of richer nations is overestimated in $10 \%$, while the wealth of the poorer countries is underestimated in $10 \%$. This divergence may be explained also by the exclusion of "other" factors from our model. As in our model only technological capabilities $(T)$ determine the wealth of nations, the technologically stronger countries tend to be overestimated. On the contrary, countries whose income depends on "other" factors have not been taken into consideration, hence the underestimation. Indeed, it is expected that our model should produce a slope greater than 1, given its assumption ("other factors" play no role). This first exercise shows us that the system tends to a stationary state (a non-chaotic state), an essential property of a working model. Figures 4 and 5 show the same simulation for GDP and GDP per capita. Figure 4 has a $R^{2}=0.98$ and Figure 5 has a $R^{2}=0.83$. Figure 4 shows a high correlation (for GDP) but such high correlations are expected in models where the scale of variables play strong role. Figure 5 shows a lower correlation for GDP per capita, because the "scale effect" of GDP is minimized by the size of population. 




Figure 4 - GDP (Y, US\$ Billion), Real and Simulated Values (1,000 Simulation Steps, Logaritmic Scale)

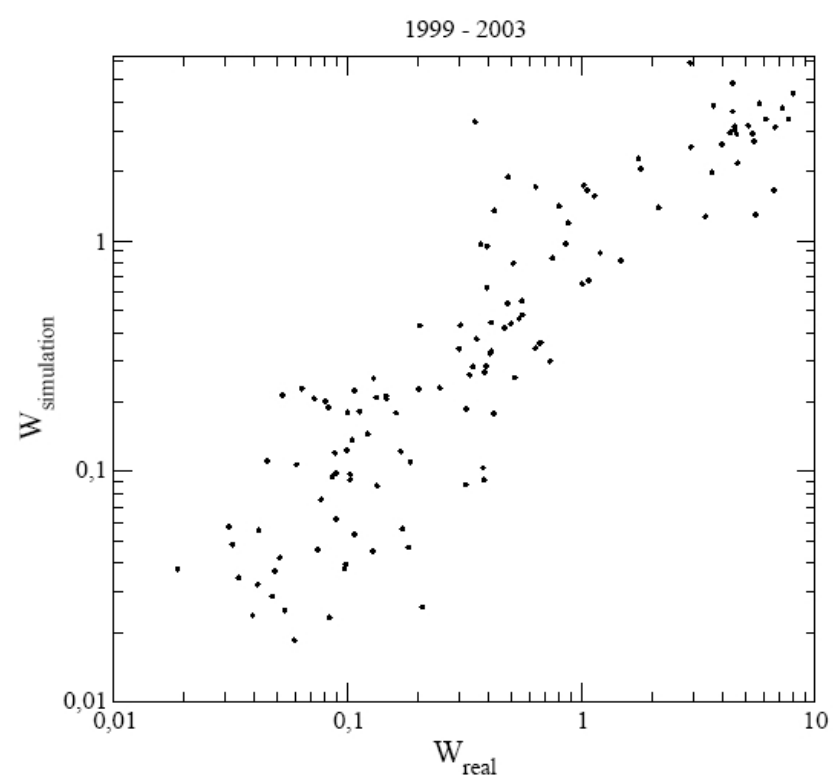

Figure 5 - GDP Per Capita (W, US\$ Billion), Real and Simulated Values (1,000 Simulation Steps, Logaritmic Scale) 


\subsection{Second Simulation: Three Different Initial GDPs}

In this second simulation exercise, we compare the correlation between the real and the simulated world created from the three initial conditions for $Y_{i}(t=0)$. Figure 6 shows the evolution of the correlation coefficient between the real and simulated wealth for these three paths: (a) open circles for initial GDPs equal to real GDPs; (b) closed circles for all countries with the same initial GDP; and (c) open squares for initially randomly selected GDPs.

Predictably, Figure 6 shows that during the first simulation steps the correlation between real and simulated GDPs are very different: high correlation for real GDPs as initial values and low correlation for the other two starting points. Asymmetric initial conditions underlie this initial different correlation. However, as the simulation evolves, the correlation values converge to the same (high) correlation value. This represents a very important point: our model is robust in relation to initial conditions. When we feed our model with the real data for population, scientific and technological production, it does not matter from where the simulation begins. That is, it will always build a simulated world that replicates the real world. In other words, these three variables are enough to define the world wealth distribution in a stationary state. All curves converge to the correlation in the neighborhood of $R^{2}=0.98$ and to a slope near 1.10 .

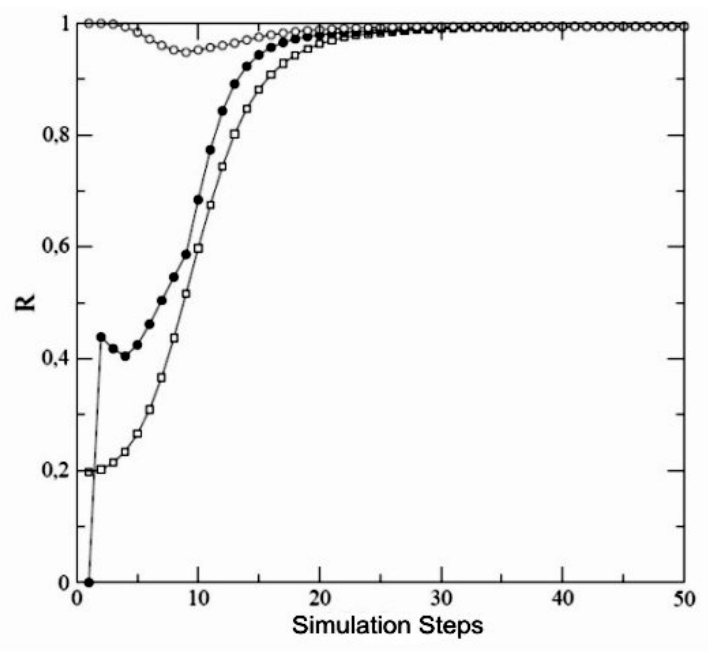

Note: Simulations starting with equal, random and real GDPs values.

This second exercise shows that the system always replicates the real world, independent of the initial conditions. As our model does not control for variables like GDP, the system is robust regarding its initial conditions.

Figure 6 - Correlation between Real and Simulated GDPs 


\subsection{Third Simulation: Real and Random Values for Population, Scientific and Techno- logical Production}

In this third simulation exercise, the initial GDPs values are the real ones. In this exercise what we change are the values for population $(L)$ and for scientific and technological production $(T)$. Figure 7 shows the correlation between the real and simulated $Y$ obtained for four different paths. During the first simulation steps the correlation is high in all four cases because the real GDPs are the starting points. Divergence regarding correlation is generated just after 40 simulation steps.

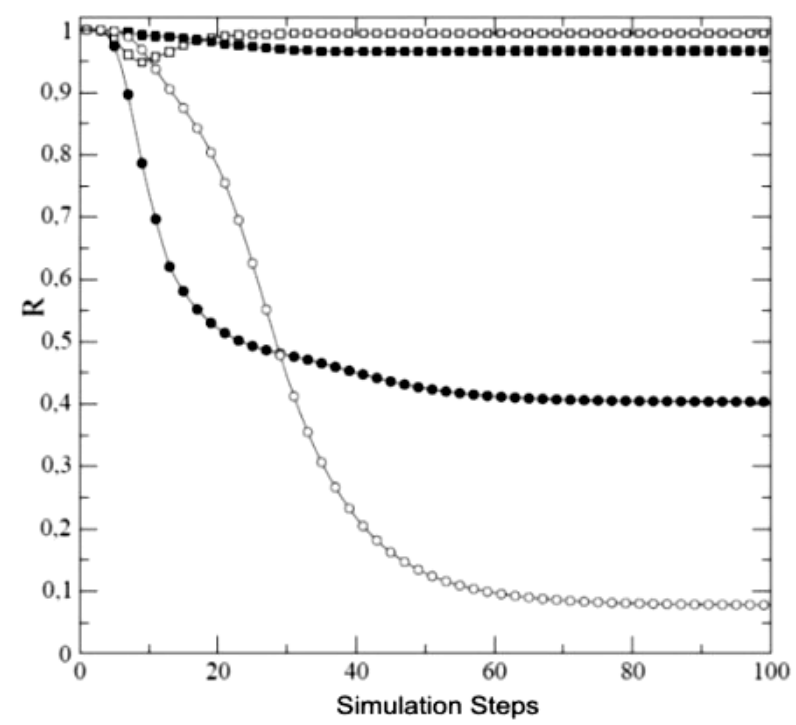

Note: Simulations starting with random and real values for population, technological and scientific production.

Figure 7 - Correlation between Real and Simulated GDPs

The first path is represented by open circles: the model is fed by random values for population and for scientific and technological production. As the system evolves, the correlation between real and simulated wealth falls, reaching $R^{2}=0.1$ around the $100^{\text {th }}$ iteration. The second path is represented by closed circles: random values for scientific and technological production but real values for population. The correlation also falls as the system evolves, but reaches $R^{2}=0.4$ around the $100^{\text {th }}$ iteration. 
In the two last paths the models are fed by real values for science and technology. In the third path, represented by full squares, populations are defined randomly. The correlation is high $\left(R^{2}=0.96\right)$ around the $100^{\text {th }}$ iteration. Finally, in the fourth path, population and science and technology are real values, and the correlation is $R^{2}=0.98$ (a correlation similar to the obtained in the two previous exercises, see topics 5.1 and 5.2, above).

The comparison between these four paths suggests the role and the weight of each variable as a determinant of the wealth of nations, stressing the importance of science and technology. This exercise is the most important to test this paper's conjecture.

In sum, this section shows us that: a) the system tends to a stationary state (a nonchaotic state); b) the system always replicates the real world, independent of the initial conditions; and c) the role and weight of science and technology as a determinant of the wealth of nations.

\section{Conclusions and Agenda for Further Research}

The findings are the following so far: (a) the data and the initial simulation supports an important role for science and technology in the determination of the wealth of nations; (b) the model is able to replicate the real world starting from the variables describing science and technology; (c) this model was tested to investigate whether or not other variables would have similar effects (the hierarchy of countries is always replicated by our model when fed by science and technology and it is not replicated when random variables are used).

Regarding the model suggested in Section 2, the simulation exercises show that it is able to replicate the world income distribution without a priori information about this distribution. That is to say: the algorithm is consistent as the results are non-trivial (stationary state is independent of initial conditions). The model simulates a world that has high correlation with the real world. In addition, the model is parsimonious, as we obtain the world income distribution $\left(\mathrm{R}^{2}=0.98\right)$ feeding the system only with data for population, patents and scientific papers.

Regarding this paper's conjecture on the role of science and technology as a determinant of the wealth of nations, the exercises show that science and technology are good proxies to guide the system to find its stationary state. Furthermore, as the third exercise shows, science and technology are more important than population to define the world's income distribution. 
Finally, this new version improves the model presented in Ribeiro et al. (2006a) because $\mathrm{T}$ is now defined in a way more in line with the evidences of the literature. While in the previous version a country only would try to improve its technological position if its income was reduced, now a country may improve its technology without suffering from income losses.

The exercises and improvements presented in this paper lead us to a baseline model, since it is able to replicate the real world (a static model). This baseline model supports a move towards a next step of our agenda: how to model a dynamic world. The goal of this dynamic model is to replicate the dynamics pinpointed by the data presented in Ribeiro et al. (2006b), for the world in 1974, 1982, 1990, 1998 and 2006. Two additional steps may be taken: (1) introduction of feedbacks from income to NSI and from NSI to income, as sketched by Bernardes and Albuquerque (2003); (2) improvements in the quantitative and formal representation of NSIs, since the interactions between science and technology must be described and measured, requiring indicators of connectivity and growth rate. These improvements in our model would open the possibility of individual time-paths that would overcome the thresholds identified by Figure 2 and would help to illustrate the changes in NSI required to achieve a successful technological catch-up.

\section{References}

AVERSI, R. et al. The dynamics of international differentiation: a multi-country evolutionary model. In: DOSI, G. Innovation, organization, and economic dynamics - selected essays. Cheltenham, UK and Northampton, MA, USA: Edward Elgar, 2000.

BERNARDES, A.T.; ALBUQUERQUE, E.M. Cross-over, thresholds, and interactions between science and technology: lessons for less-developed countries. Research Policy, 32, p. 865-885, 2003.

CHIAROMONTE, F.; DOSI, G.; ORSENIGO, L. Innovative learning and institutions in the process of development: on the microfundations of growth regimes. In: DOSI, G. Innovation, organization, and economic dynamics - selected essays. Cheltenham, UK; Northampton, MA, USA: Edward Elgar, 2000.

DOSI, G. Sources, procedures and microeconomic effects of innovation. Journal of Economic Literature, v. 27, p. 1126-1171, 1988.

Opportunities, incentives and collective patterns of technological change. The Economic Journal, v. 107, p. 1530-1547, 1997.

. Innovation, organization, and economic dynamics - selected essays. Cheltenham, UK; Northampton, MA, USA: Edward Elgar, 2000. 
DOSI, G.; FREEMAN, C.; FABIANI, S. The process of economic development: introducing some stylised facts and theories on technologies, firms and institutions. Industrial and Corporate Change, v. 3, n. 1, 1994.

DOSI, G. et al. (Ed.). Technical change and economic theory. London: Pinter, 1988.

EDQUIST, C. (Ed.). Systems of innovation: technologies, institutions and organizations. London: Pinter, 1997.

FAGERBERG, J. Technology and international differences in growth rates. Journal of Economic Literature, v. 32, Sept. 1994.

. ; MOWERY, D.; NELSON, R. The Oxford Handbook of Innovation. Oxford: Oxford University Press, 2005.

FREEMAN, C. The economics of industrial innovation. London: Pinter, 1974.

. Japan: a new national system of innovation? In: DOSI, G. et al. (Ed.). Technical change and economic theory. London: Pinter, 1988, p. 330-348.

. The economics of technical change: critical survey. Cambridge Journal of Economics, v. 18, p. 463-514, 1994.

. The "National System of Innovation" in historical perspective. Cambridge Journal of Economics, v. 19, n. 1, 1995.

FREEMAN, C.; SOETE, L. The economics of industrial innovation. London: Pinter, 1997.

ISI -Institute of Scientific Information, 2005. Available at: http://portal.isiknowledge.com. Access in: 19/08/2008.

LUNDVALL, B-A Innovation as an interactive process: from user-producer interaction to the national system of innovation. In: DOSI, G. et al. (Ed.). Technical change and economic theory. London: Pinter, 1988, p. 349-369.

. (Ed.). National systems of innovation: towards a theory of innovation and interactive learning. London: Pinter, 1992.

MOED, H.; GLÄNZEL, W.; SCHMOCH, U. (Ed.). Handbook of quantitative science and technology research: the use of publication and patent statistics in studies of S\&T systems. Dordrecht: Kluwer Academic Publishers, 2004.

NARIN, F.; HAMILTON, K. S.; OLIVASTRO, D. The increasing linkage between U.S. technology and public science. Research Policy, v. 26, n. 3, p. 317-330, 1997.

NELSON, R. Institutions supporting technical change in the United States. In: DOSI, G. et al. (Ed.). Technical change and economic theory. London: Pinter, 1988, p. 312-329.

(Ed.). National innovation systems: a comparative analysis. New York, Oxford: Oxford University, 1993. 
. Recent evolutionary theorizing about economic change. Journal of Economic Literature, v. XXXIII, p. 48-90, March 1995.

. The agenda for growth theory: a different point of view. Cambridge Journal of Economics, v. 22, p. 497-520, 1998.

. Economic development from the perspective of evolutionary economic theory. 2004. Available at: < http://www.globelics-beijing.cn/paper/Richard\%20R\%20 Nelson.pdf. Access in: 19/08/2008.

NELSON; WINTER, S. In search of useful theory of innovation. Research Policy, v. 6, n. $5,1977$. 1982.

. An evolutionary theory of economic change. Cambridge: Harvard University, . Evolutionary theorizing in economics. Journal of Economic Perspectives, v. 16, n. 2, p. 23-46, 2002.

POSSAS, M.L. et al. Um modelo evolucionário setorial. Revista Brasileira de Economia, v. 55, n. 3, p. 333-377, 2001.

RIBEIRO, L. C. et al. National systems of innovation and technological differentiation: a multi-country model. International Journal of Modern Physics C, v. 17, n. 2, p. 247-257, 2006a.

. Science in the developing world: running twice as fast? Computing in Science and Engineering, v. 8, p. 81-87, July 2006b.

ROSENBERG, N. Perspectives on technology. Cambridge: Cambridge University, 1976.

RUIZ et al. Modelling the role of national system of innovation in economical differentiation. In: GARRIDO, P. L.; MARRO, J.; MUOZ, M. A. (Ed.). Modeling cooperative behavior in the social sciences. In: EIGHTH GRANADA LECTURES, 7-11 February 2005, Granada, Spain. Proceedings... Melville: American Institute of Physics, 2005.

SCHUMPETER, J. A. Theory of economic development. Cambridge: Harvard University Press, 1911.

SILVERBERG, G.; DOSI, G.; ORSENIGO, L. Innovation, diversity and diffusion: a self-organisation model. The Economic Journal, 98, p.1032-1054, Dec. 1988.

SILVERBERG, G.; SOETE, L. The economics of growth and technical change: technologies, nations, agents. Ipswich: Edward Elgar, 1994.

SILVERBERG, G.; VERSPAGEN, B. A percolation model of innovation in complex technology spaces. Journal of Economic Dynamics \& Control, v. 29, p. 225-244, 2005.

USPTO - United States Patent and Trademark Office. 2001. Available at: <http:// www.uspto.gov>. Access in: 19/08/2008. 
WINTER, S.G.; KANIOVSKI, Y.M.; DOSI, G. Modeling industrial dynamics with innovative entrants. Structural Change and Economic Dynamics, 11, 2000, p. 255-293, 2000.

WORLD BANK. Statistical information. 2005. Available at: < http://www.worldbank. org >. Access in: 19/08/2008. 